\title{
Análise Citotóxica e Mutagênica do Extrato Aquoso de Maytenus guya- nensis Klotzsch Ex Reissek (Celastraceae) Chichuá (Xixuá) Amazônico
}

\author{
Analysis cytotoxic and mutagenic the Aqueous Extract of Maytenus guyanensis \\ Klotzsch Ex Reissek (Celastraceae) Chichuá (Xixuá) Amazon
}

\author{
Dionatas Ulises de Oliveira Meneguetti ${ }^{1}$, Renato Abreu Lima ${ }^{2}$, Jaqueline Barbosa da Silva ${ }^{3}$, \\ Ramaele Pereira da Silva ${ }^{4}$, Rubiani de Cassia Pagotto ${ }^{5}$, Valdir Alves Facundo ${ }^{6}$. \\ ${ }^{1}$ Doutorando, Universidade Federal do Acre (UFAC), Rio Branco - Acre- Brasil \\ ${ }^{2}$ Doutorando, Rede de Biodiversidade e Biotecnologia da Amazônia Legal, Porto Velho - Rondônia - Brasil \\ ${ }^{3,4}$ Graduanda, Faculdades Integradas Aparício Carvalho, FIMCA, Porto Velho - RO - Brasil \\ ${ }^{5}$ Doutora, Departamento de Biologia, Universidade Federal de Rondônia, Porto Velho - RO - Brasil \\ ${ }^{6}$ Doutor, Departamento de Química, Universidade Federal de Rondônia, Porto Velho - RO - Brasil
}

\begin{abstract}
Resumo
O gênero Maytenus é o maior da família Celastraceae com cerca de 225 espécies. Maytenus guyanensis é uma árvore endêmica de terra firme na Amazônia, e conhecida como chichuá, xixuá, chuchahuasi, chucchu huashu, chuchuasi e chuchasha. Suas raízes e caule são utilizados como analgésico, anti-inflamatório, afrodisíaco, relaxante muscular, antirreumático, antidiarreico e antiparasitário sendo também indicada no tratamento de artrite, impotência, resfriado, bronquite, hemorroidas e câncer. O presente estudo objetivou realizar uma análise citotóxica e mutagênica do extrato aquoso de M. guyanensis. Os métodos utilizados foram: índice mitótico, germinação dos meristemas e análise de micronúcleo em Allium cepa. Constatou-se que o extrato aquoso da entrecasca M. guyanensis nas concentrações de 3,85 e 38,5 mg/mL não apresenta ação citotóxica e mutagênica, e ainda atuam como anticitotóxico e antimutagênico. O tratamento de $77 \mathrm{mg} / \mathrm{mL}$ demonstrou ter ação citotóxica, e anticitotóxica na presença de paracetamol, porém sem ação mutagênica e antimutagênica. A concentração de $192 \mathrm{mg} / \mathrm{mL}$ demonstrou ser citotóxica e mutagênica. O estudo demonstrou a incolumidade em relação aos efeitos citotóxicos e mutagênicos no uso tradicional M. guyanensis, sendo indicados estudos futuros in vitro (linfócitos) e in vivo (camundongos) para uma melhor compreensão dos efeitos fisiológicos dos extratos e compostos isolados, e até mesmo para o desenvolvimento de um fitoterápico ou fármaco tendo esta espécie como matéria prima.
\end{abstract}

Palavras-chave: Citotoxicidade, Mutagenicidade, Maytenus guyanensis.

\begin{abstract}
The Maytenus genus is the largest in the Celastraceae family this comprises about 225 species. Maytenus guyanensis is an endemic tree of dry land in the Amazon, and known as chichuá, xixuá, chuchahuasi, chucchu Huashu, chuchuasi and chuchasha. Its roots and stems are used as analgesic, anti-inflammatory, aphrodisiac, muscle relaxant, antirheumatic, antidiarrheal and anti-interference is also indicated for the treatment of arthritis, impotence, flu, bronchitis, hemorrhoids and cancer. This study aimed to perform a cytotoxic and mutagenic analysis of aqueous extract of M. guyanensis. The methods used were: mitotic index, germination of meristems and analysis of micronucleus in Allium cepa. It was found that the aqueous extract of $M$. guyanensis bark at concentrations of 3.85 and $38.5 \mathrm{mg} / \mathrm{mL}$ does not presented cytotoxic and mutagenic action, and also acted as anticitotóxico and antimutagenic. The treatment of $77 \mathrm{mg} / \mathrm{mL}$ demonstrated to have effects cytotoxic and anticitotóxica in the presence of paracetamol, this concentration showed no mutagenic and antimutagenic action. The concentration of $192 \mathrm{mg} / \mathrm{mL}$ was identified action cytotoxic and mutagenic. The study demonstrated the safety cytotoxic and mutagenic of use traditional of M. guyanensis. Future studies are indicated in vitro (lymphocytes) and in vivo (mice) for a better understanding of the physiological effects of extracts and isolated compounds for better conclusions on the safe use of the same, and even the development of a herbal drug or taking this species as raw material.
\end{abstract}

Keywords: Cytotoxicity, Mutagenicity, Maytenus guyanensis. 


\section{Introdução}

A utilização de plantas com fins medicinais para tratamento, cura e/ou prevenção de doenças é uma das mais antigas formas de prática medicinal da humanidade (DUTRA, 2009). Os produtos naturais desempenham um papel importante na descoberta e desenvolvimento de novas entidades químicas como materiais de partida para a síntese de drogas mais específicas e eficientes (LANG et al., 2008). A flora brasileira possui ampla utilização pela população, mas existe o consenso da insuficiência de estudos científicos acerca do assunto (SILVA et al., 2012), principalmente se tratando da segurança e efetividade dos produtos naturais (BRASIL, 1996; FDA, 2008), sendo imprescindível a realização de testes toxicológicos e mutagênicos. Vários autores salientaram a importância e a utilidade de testes com vegetais na avaliação de riscos de genotoxicidade, pois apesar das diferenças entre os metabolismos de plantas e animais os resultados mutagênicos possuem alta compatibilidade (HURTADO, 2013; BAGATINI et al., 2007; FISKESJO, 1994).

Entre os modelos vegetais, o sistema teste Allium cepa apresenta-se como um bioindicador ideal para o primeiro screening da genotoxicidade de extrato de plantas medicinais, devido ao seu baixo custo, confiabilidade e concordância com outros testes de genotoxicidade (FÃO et al., 2012; POLETTO et al., 2011; BAGATINI et al., 2007), como observado por Teixeira et al. (2003) em extratos de Psidium guajava L. e Achillea millefolium L. em três sistemas testes: células meristemáticas de A. cepa, células da medula óssea de ratos e linfócitos humanos, sendo observado resultados antimutagênicos dessas espécies nos três sistemas testados, demonstrando a equivalência entre os mesmos.

O Brasil possui quase $19 \%$ da flora mundial, sendo a Floresta Amazônica, uma das mais ricas e diversificadas do mundo, onde cerca de $99 \%$ das plantas medicinais não têm sua eficácia e segurança farmacológica comprovada (GIULIETTI et al., 2005; FÃO et al., 2012).

A família Celastraceae é encontrada principalmente em regiões tropicais, estando representadas por 98 gêneros e aproximadamente 1.264 espécies, caracterizadas em seus habitats naturais como árvores, arbustos, trepadeiras e cipós (LORENZI \& MATOS, 2008). No Brasil, os gêneros mais representativos da família Celastraceae são: Maytenus e Salacia, respectivamente (LIÃO, 1994). Muita atenção têm sido dada às espécies desta família, devido ao seu amplo leque de atividades biológicas descritos na literatura (FONSECA et al., 1997; LIÂO et al., 1997; RODRIGUES et al., 2006).

Maytenus guyanensis é uma árvore endêmica de terra firme na Amazônia, conhecida como chichuá, xixuá, chuchahuasi, chucchu huashu, chuchuasi e chuchasha (REVILLA, 2002; BORRÁS, 2003). Suas raízes e caule são utilizados como analgésico, anti-inflamatório, afrodisíaco, relaxante muscular, antireutmático e antidiarréico (BORRÁS, 2003). Como cosmético é utilizado nas erup- ções cutâneas e prevenção de câncer de pele (REVILLA, 2002). O uso de antioxidantes naturais tem aumentado com as descobertas das propriedades dos componentes que são produzidos pelas plantas por meio do metabolismo secundário, devido a atuação como agentes redutores, sequestradores de radicais livres, quelantes de metais ou desativadores do oxigênio singleto e/ou exibir simultaneamente, mais de uma dessas funções (CANTERLE, 2005).

O presente estudo objetivou realizar uma análise citotóxica e mutagênica do extrato aquoso de M. guyanensis, com o intuito de averiguar a possível incolumidade do uso tradicional dessa espécie.

\section{Material e métodos}

\subsection{Coleta e identificação do material vegetal}

As entrecascas de $M$. guyanensis foram coletadas em fevereiro de 2008 na Reserva Florestal Adolpho Ducke, localizada no Km 26 da Estrada Manaus-Itacoatiara (AM010) (Lat $02^{\circ} 53^{\prime} 20^{\prime \prime}$ S, Long 59 $58^{\prime} 54^{\prime \prime} \mathrm{W}$ ). A identificação da espécie foi realizada no Herbário do Instituto Nacional de Pesquisa da Amazônia (INPA), exsicata ㄲo 188.485.

\subsection{Preparo do extrato}

A entrecasca de M. guyanensis foi triturada para aumentar a superfície de contato com o solvente. O extrato foi preparado por meio de maceração em $\mathrm{H} 2 \mathrm{O}$ mineral por 72 horas, nas seguintes concentrações: $(3,85 \mathrm{mg} / \mathrm{mL})$ normalmente utilizada pela população, $(38,5 \mathrm{mg} / \mathrm{mL})$ 10 vezes mais concentrada, $(77 \mathrm{mg} / \mathrm{mL}) 20$ vezes mais concentrada e $(192 \mathrm{mg} / \mathrm{mL}) 50$ vezes mais concentrada (CAMPAROTO et al., 2002).

\subsection{Análise citotóxica e mutagênica}

O experimento utilizou a espécie Allium cepa, (conhecida popularmente como cebola de cabeça) orgânica de tamanho uniforme, de mesma origem, não germinadas e saudáveis.

Em cada concentração e controles foram utilizadas 10 bulbos e $A$. cepa, sendo estes submersos para germinação em $50 \mathrm{~mL}$ dos extratos em estudo a $24 \mathrm{C}^{\circ}$, durante 72 horas.

Foram utilizados os seguintes tratamentos: Controle Negativo $(\mathrm{CN})$ contendo $\mathrm{H}_{2} \mathrm{O}$ mineral e Controle Positivo $(\mathrm{CP})$ contendo paracetamol diluído na concentração de $800 \mathrm{mg} / \mathrm{L}$, esta que é descrita como citotóxica e mutagênica (BESSEMS et al., 1995; STURBELLE et al., 2008; DÜSMAN et al., 2012). Para os testes citotóxicos e mutagênicos foi utilizado o $\mathrm{CN}$ e o extrato aquoso de M. guyanensis nas seguintes concentrações: $3,85 \mathrm{mg} / \mathrm{mL}$, $38,5 \mathrm{mg} / \mathrm{mL}, 77 \mathrm{mg} / \mathrm{mL}$ e $192 \mathrm{mg} / \mathrm{mL}$. Já para os testes anticitotóxicos e antimutagênicos foram utilizadas as 


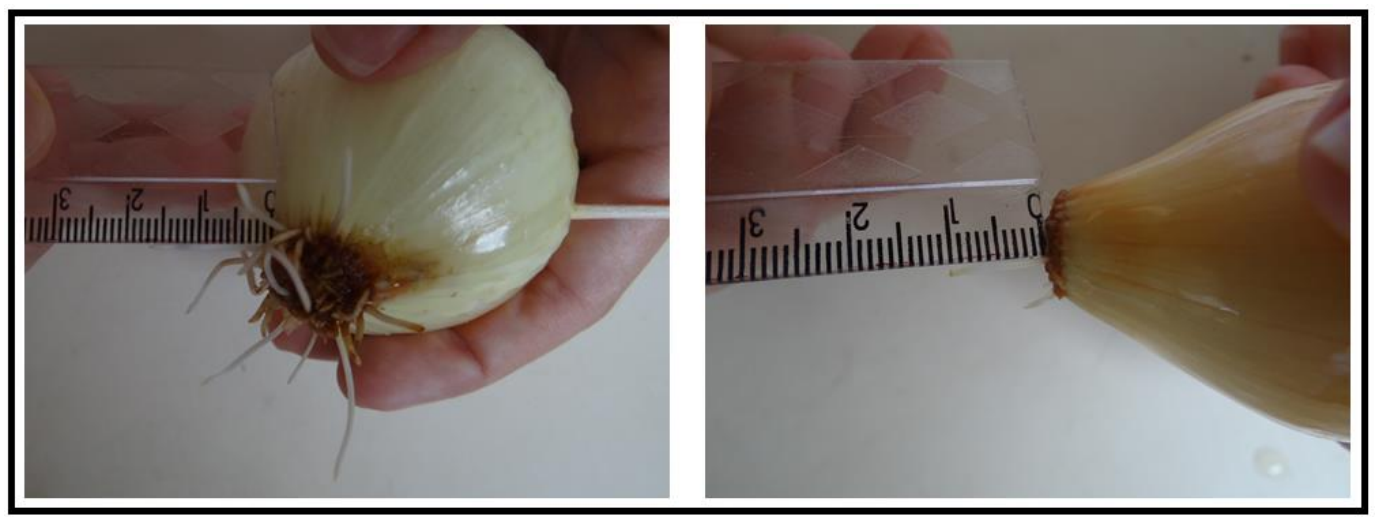

Figura 1. Medição das raízes de $A$. cepa.

mesmas concentrações do extrato aquoso de $M$. guyanensis descrito acima, adicionado do CP.

\subsubsection{Análise Citotóxica}

A análise citotóxica em $A$. cepa foi realizada com base na germinação dos meristemas (FISKESJÖ, 1985). As raízes foram medidas com 72 horas, após o início da germinação.

De cada bulbo de $A$. cepa foram medidas as três maiores raízes, totalizando 30 raízes por tratamento. A medição foi realizada com régua escolar simples graduada em cm (Figura 1).

\subsubsection{Análise Mutagênica e Índice Mitótico}

Em torno de $72 \mathrm{~h}$ após o início do teste, os meristemas foram coletados com 0,1 a 2,5 cm de comprimento, lavados em água destilada, seguida de hidrólise com HCL $1 \mathrm{~N}$ por 10 minutos em banho-maria a $60 \mathrm{C}^{\mathrm{o}}$, sendo os tubos resfriados em água corrente.

Após nova lavagem dos meristemas hidrolisados em água destilada foram realizados esfregaços em duas lâminas por bulbo (totalizando 20 lâminas por tratamento), postas em seguida sob gelo seco por um minuto para retirada da lamínula e aguardado por 30 minutos em temperatura ambiente para secagem. Em seguida, as mesmas foram coradas conforme Meneguetti et al. (2012), utilizando o kit Panótico Rápido composto de três recipientes: primeiro triarilmetano a $0,1 \%$, segundo xantenos a $0,1 \%$ e terceiro tiazinas a $0,1 \%$, sendo as lâminas submersas 10 vezes em cada recipiente com submersões de 1 segundo de duração na sequência descrita acima (OLIVEIRA; YAMASHITA; MENEGUETTI, 2013; FÃO et al., 2012; SILVA et al., 2012; POLETTO et al., 2011).

Posteriormente as lâminas foram lavadas em água deionizada com o $\mathrm{pH}$ 7,0 e secas em temperatura ambiente. Em cada lâmina foram contadas mil células e quantificado a quantidade de micronúcleos (Figura.2) e o percentual de células em interfase e mitose.

\subsection{Análise estatística}

Utilizou-se o software Graphad Prism 5.0 sendo aplicada a Análise de Variância (ANOVA) e o teste Tukey, sendo considerado significante a partir de $\mathrm{P}<0,05$.

Para o calculo de Índice Mitótico aplicou-se a seguinte equação: (Número Total de Células em Mitose $\div$ Número Total de Células × 100).

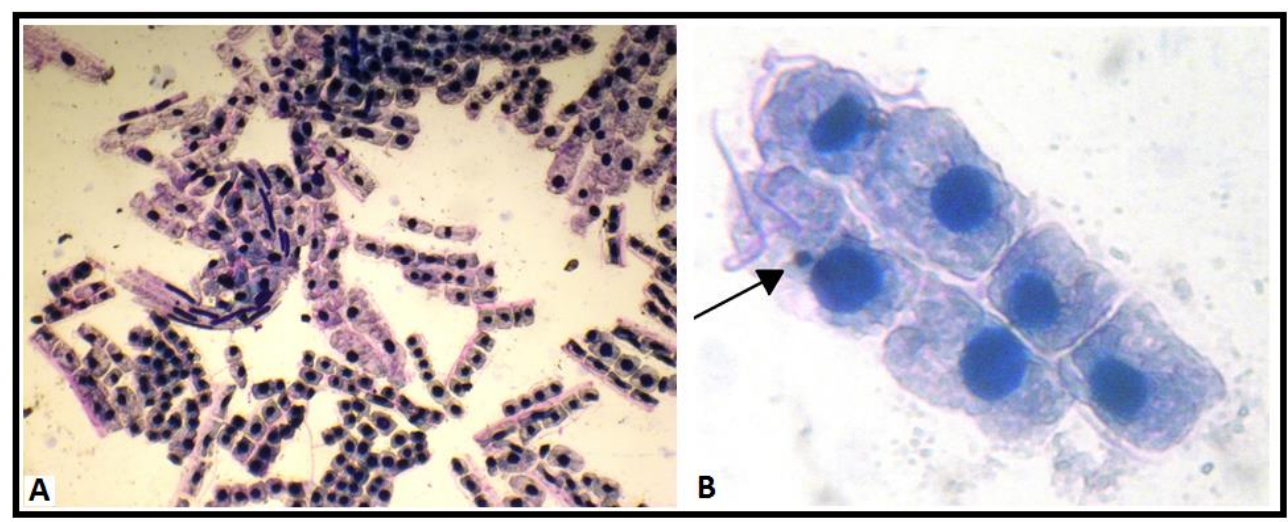

Figura 2. A - Células de A. cepa, aumento de 100X, B - Micronúcleo em célula de A. cepa, aumento de 400X (MENEGUETTI et al., 2012). 


\section{Resultados e discussão}

Os resultados obtidos por meio das análises toxicológicas, antitoxicológicas, mutagênicas e antimutagênicas do extrato aquoso de M. guyanensis, são mostrados na Tabela 1.

Os dados mostram que o extrato aquoso de M. guyanensis apresenta ação citotóxica nas concentrações de 77 e 192mg/mL ( $\mathrm{P}<0,001)$, (Tabela 1; Figura 3 a), o que não é preocupante visto que essas concentrações são, respectivamente, 20 vezes mais concentradas que a usualmente utilizadas pela população que é $3,85 \mathrm{mg} /$ $\mathrm{mL}$ (CAMPAROTO et al., 2002). Nas concentrações de 3,85 e $38,5 \mathrm{mg} / \mathrm{mL}$, os extratos apresentaram ação antitoxicológica $(\mathrm{P}<0,001)$, contra os efeitos ocasionado pelo paracetamol na concentração de $800 \mathrm{mg} / \mathrm{L}$ conforme foi observado no CP (Figura 3 b). Na concentração de $77 \mathrm{mg} / \mathrm{mL}$ observou-se ação tóxica, bem como ação antitoxicológica $(\mathrm{P}<0,05)$, demonstrando que houve uma interação benéfica com o CP.

Os resultados da toxicidade e antitoxicidade dos diferentes tratamentos sobre o ciclo celular de A. cepa podem ser observados na Figura 4 e Tabela 2.

Os resultados mostraram que o tratamento de $3,85 \mathrm{mg} /$ $\mathrm{mL}$ aumentou a divisão celular de maneira significativa $(\mathrm{P}<0,001)$, diferentemente das concentrações de $77 \mathrm{mg} / \mathrm{mL}$ $(\mathrm{P}<0,05)$ e $192 \mathrm{mg} / \mathrm{mL}(\mathrm{P}<0,001)$, que demonstraram ação antiproliferativa do índice mitótico. Esses dados corroboram com os resultados de efeitos tóxicos ocasionados pela concentração de $77 \mathrm{mg} / \mathrm{mL}$ (Tabela 1; Figura 3 a).

Os tratamentos de $3,85 \mathrm{mg} / \mathrm{mL}(\mathrm{P}<0,001), 38,5 \mathrm{mg} /$ $\mathrm{mL}(\mathrm{P}<0,001)$ e $77 \mathrm{mg} / \mathrm{mL}(\mathrm{P}<0,05)$ apresentaram ação inibitória dos efeitos ocasionados pelo $\mathrm{CP}$, estando de acordo também com os testes antitoxicológicos descritos anteriormente.

O único tratamento que apresentou ação mutagênica foi o de $192 \mathrm{mg} / \mathrm{mL}(\mathrm{P}<0,001)$ (Figura 5 a), sendo observada nesta concentração algumas pontes anafásicas (Figura 4 i), que são alterações ocorrentes devido a mutagenicidade (STURBELLE et al., 2008).
Nos testes de antimutagenicidade os resultados coincidiram com os de antitoxicidade, tendo ação significante as concentrações de 3,85 e $38,5 \mathrm{mg} / \mathrm{mL}(\mathrm{P}<0,001)$ (Figura $5 \mathrm{~b}$ ).

O extrato aquoso da entrecasca $M$. guyanensis nas concentrações de 3,85 e 38,5 mg/mL não apresenta ação citotóxica e mutagênica, e ainda atuam como anticitotóxico e antimutagênico, porém mesmo nessas concentrações é indicado estudos de biacumulação, para um melhor entendimento dos efeitos da utilização desses extratos vegetais a longo prazo (SILVA; FERREIRA, 2003).

O tratamento de $77 \mathrm{mg} / \mathrm{mL}$ demonstrou ter ação citotóxica e anticitotóxica na presença de paracetamol, porém não demonstrou ação mutagênica e antimutagênica. A concentração de $192 \mathrm{mg} / \mathrm{mL}$ demonstrou ser citotóxica e mutagênica. Mesmo com potencial citotóxico e mutagênico dessas concentrações, é improvável a ocorrência de ação negativa no corpo humano, visto que a dose utilizada pelas populações tradicionais é 50 vezes inferior a concentração de $192 \mathrm{mg} / \mathrm{mL}$.

Os resultados acima descritos estão de acordo com estudo realizado por Hurtado (2013), onde nos testes de atividade genotóxica o extrato acetônico da entrecasca e os eluatos de $M$. guyanensis demonstraram atividade antiproliferativa com tempo de exposição prolongado, não apresentando ação clastogênica e aneugênica. Resultado semelhante também foi observado na espécie $M$. senegalensis, que não apresentou atividade mutagênica (REID et al., 2006).

Em outro estudo a análises de células meristemáticas de $A$. cepa demonstrou que concentrações mais elevadas de extrato de M. ilicifolia promoveram redução no índice mitótico e nenhum surgimento de alterações cromossômicas (CAMPARATO et al., 2002). Entretanto, Souza et al. (2005) demonstraram que na concentração de 40 $\mathrm{mg} / \mathrm{mL}$, houveram alterações cromossômicas (pontes anafásicas) que também foi observado no tratamento de $192 \mathrm{mg} / \mathrm{mL}$ do presente estudo, sugerindo um potencial genotóxico e efeito alelopático que podem ser explicado pela presença de saponinas, taninos e flavonas ocorren-

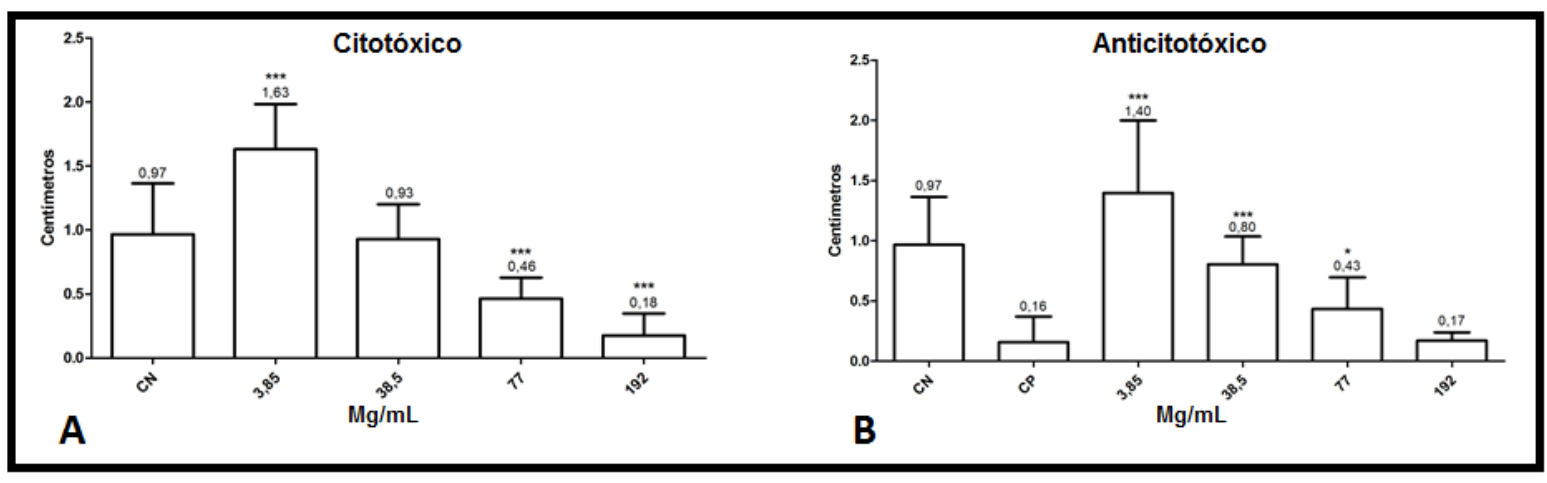

Figura 3. A e B) Média do tamanho da germinação dos meristemas de $A$. cepa, para análise citotóxica e anticitotóxica. ${ }^{*}(\mathrm{P}<0,05),{ }^{* *}(\mathrm{P}<0,01) \mathrm{e}^{* * *}(\mathrm{P}<0,001)$. CN: Controle negativo. CP: Controle positivo. 
Tabela 1. Germinação em das raízes de A. cepa (toxicidade e antitoxicidade) e número de micronúcleos por 1000 células (mutagenicidade e antimutagenicidade). (Concentrações em mg/mL).

\begin{tabular}{|c|c|c|c|c|c|c|c|c|c|c|c|}
\hline \multirow[b]{2}{*}{$\begin{array}{c}\text { Espécimes } \\
\text { (А. серa) }\end{array}$} & \multicolumn{5}{|c|}{ Toxicidade } & \multicolumn{6}{|c|}{ Antitoxicidade } \\
\hline & $\mathrm{CN}$ & 3,85 & 38,5 & 77 & 192 & $\mathrm{CN}$ & CP & 385 & 38.5 & 77 & 192 \\
\hline \multirow[t]{3}{*}{1} & 1,5 & $\begin{array}{l}0,03 \\
1,8\end{array}$ & 0,5 & 0,4 & 0,2 & 1,5 & 1,1 & $\begin{array}{l}3,03 \\
2,4\end{array}$ & $\begin{array}{c}0,3 \\
1,1\end{array}$ & 0,3 & 0,2 \\
\hline & 1,6 & 1,9 & 0,8 & 0,5 & 0,1 & 1,6 & 0,4 & 2,2 & 0,9 & 0,2 & 0,2 \\
\hline & 1,5 & 1,1 & 0,8 & 0,4 & 0,1 & 1,5 & 0,1 & 2 & 0,9 & 0,2 & 0,1 \\
\hline \multirow[t]{3}{*}{2} & 1,5 & 1,1 & 0,8 & 0,8 & 0,2 & 1,5 & 0 & 0,5 & 0,6 & 0,3 & 0,2 \\
\hline & 1,3 & 1,4 & 0,9 & 0,4 & 0,2 & 1,3 & 0 & 0,4 & 0,9 & 0,3 & 0,1 \\
\hline & 0,9 & 1 & 1,4 & 0,3 & 1 & 0,9 & 0 & 0,4 & 0,8 & 0,3 & 0,1 \\
\hline \multirow[t]{3}{*}{3} & 1,3 & 2 & 0,8 & 0,8 & 0,2 & 1,3 & 0,1 & 1,6 & 0,6 & 0,4 & 0,3 \\
\hline & 1,2 & 2 & 1,5 & 0,6 & 0,1 & 1,2 & 0,1 & 1,4 & 0,6 & 0,1 & 0,3 \\
\hline & 1,4 & 2,1 & 1,5 & 0,7 & 0,1 & 1,4 & 0,1 & 1,3 & 0,5 & 0,1 & 0,3 \\
\hline \multirow[t]{3}{*}{4} & 0,5 & 1,9 & 0,8 & 0,5 & 0,2 & 0,5 & 0,1 & 2 & 0,4 & 0,4 & 0,2 \\
\hline & 0,8 & 1,6 & 0,9 & 0,6 & 0,2 & 0,8 & 0,3 & 1,9 & 0,4 & 0,3 & 0,1 \\
\hline & 1 & 1,9 & 0,8 & 0,6 & 0,2 & 1 & 0,4 & 1,8 & 0,4 & 0,1 & 0,1 \\
\hline \multirow[t]{3}{*}{5} & 0,6 & 1,9 & 1,1 & 0,6 & 0,1 & 0,6 & 0,2 & 0,7 & 1,2 & 0,4 & 0,2 \\
\hline & 0,5 & 1,7 & 1 & 0,5 & 0,1 & 0,5 & 0,4 & 1 & 1,1 & 0,6 & 0,2 \\
\hline & 0,5 & 1,9 & 1 & 0,5 & 0,1 & 0,5 & 0,2 & 0,6 & 1,1 & 0,3 & 0,2 \\
\hline \multirow[t]{3}{*}{6} & 0,8 & 1,5 & 0,9 & 0,3 & 0 & 0,8 & 0 & 1,2 & 0,6 & 0,8 & 0,1 \\
\hline & 0,9 & 1,2 & 0,9 & 0,3 & 0,1 & 0,9 & 0 & 1,1 & 0,6 & 1 & 0,1 \\
\hline & 0,8 & 1,2 & 0,8 & 0,2 & 0,1 & 0,8 & 0 & 0,9 & 0,5 & 0,7 & 0,2 \\
\hline \multirow[t]{3}{*}{7} & 0,6 & 1,4 & 0,9 & 0,4 & 0,2 & 0,6 & 0,2 & 0,8 & 1 & 0,5 & 0,2 \\
\hline & 0,9 & 1,5 & 0,8 & 0,4 & 0,2 & 0,9 & 0,1 & 0,8 & 0,9 & 0,3 & 0,2 \\
\hline & 0,9 & 1,2 & 1 & 0,3 & 0,2 & 0,9 & 0,2 & 0,9 & 0,8 & 0,2 & 0,3 \\
\hline \multirow[t]{3}{*}{8} & 1,4 & 1,1 & 1,2 & 0,2 & 0,1 & 1,4 & 0,1 & 2 & 1 & 0,9 & 0,1 \\
\hline & 0,4 & 1,8 & 1,2 & 0,2 & 0,1 & 0,4 & 0 & 1,3 & 1,1 & 0,8 & 0,1 \\
\hline & 0,2 & 1,9 & 1,5 & 0,3 & 0 & 0,2 & 0 & 1,1 & 0,8 & 0,9 & 0,2 \\
\hline \multirow[t]{3}{*}{9} & 1,5 & 1,9 & 0,6 & 0,6 & 0,3 & 1,5 & 0,1 & 1,9 & 0,9 & 0,7 & 0,2 \\
\hline & 1,4 & 2,3 & 0,7 & 0,6 & 0,2 & 1,4 & 0,1 & 1,8 & 1 & 0,6 & 0,2 \\
\hline & 0,8 & 1,8 & 0,8 & 0,6 & 0,3 & 0,8 & 0,1 & 2,1 & 0,9 & 0,6 & 0,1 \\
\hline \multirow[t]{3}{*}{10} & 0,5 & 1,5 & 0,8 & 0,4 & 0,1 & 0,5 & 0,1 & 1,9 & 0,8 & 0,2 & 0,1 \\
\hline & 0,8 & 1,4 & 0,6 & 0,5 & 0,2 & 0,8 & 0,1 & 2 & 0,9 & 0,2 & 0,1 \\
\hline & 1 & 1,9 & 0,6 & 0,4 & 0,1 & 1 & 0,1 & 1,9 & 0,8 & 0,3 & 0,1 \\
\hline \multirow[t]{3}{*}{ Média } & 0,97 & 1,63 & 0,93 & 0,46 & 0,18 & 0,97 & 0,16 & 1,4 & 0,8 & 0,43 & 0,17 \\
\hline & \multicolumn{5}{|c|}{ Mutagenicidade } & & & atimut & nicida & & \\
\hline & $\mathrm{CN}$ & 3,85 & 38,5 & 77 & 192 & $\mathrm{CN}$ & $\mathrm{CP}$ & 3,85 & 38,5 & 77 & 192 \\
\hline 1 & 3 & 0 & 0 & 0 & 7 & 3 & 6 & 4 & 3 & 12 & 8 \\
\hline & 0 & 0 & 0 & 0 & 8 & 0 & 10 & 3 & 4 & 9 & 8 \\
\hline 2 & 0 & 0 & 0 & 3 & 9 & 0 & 8 & 1 & 6 & 3 & 6 \\
\hline & 0 & 0 & 0 & 4 & 9 & 0 & 8 & 0 & 2 & 2 & 8 \\
\hline 3 & 0 & 0 & 0 & 0 & 8 & 0 & 7 & 2 & 8 & 8 & 9 \\
\hline & 0 & 0 & 5 & 0 & 7 & 0 & 9 & 2 & 8 & 7 & 8 \\
\hline 4 & 0 & 2 & 0 & 0 & 6 & 0 & 5 & 1 & 6 & 6 & 11 \\
\hline & 0 & 0 & 0 & 4 & 5 & 0 & 6 & 0 & 4 & 5 & 9 \\
\hline 5 & 3 & 5 & 5 & 3 & 5 & 3 & 4 & 0 & 6 & 9 & 6 \\
\hline & 4 & 5 & 0 & 1 & 4 & 4 & 9 & 2 & 2 & 9 & 6 \\
\hline 6 & 3 & 7 & 0 & 4 & 5 & 3 & 8 & 1 & 3 & 3 & 7 \\
\hline & 2 & 4 & 0 & 0 & 4 & 2 & 5 & 3 & 4 & 5 & 5 \\
\hline 7 & 2 & 0 & 0 & 0 & 6 & 2 & 5 & 0 & 3 & 4 & 6 \\
\hline & 3 & 0 & 0 & 0 & 8 & 3 & 9 & 1 & 4 & 8 & 4 \\
\hline 8 & 0 & 0 & 0 & 0 & 8 & 0 & 10 & 1 & 5 & 6 & 8 \\
\hline & 1 & 0 & 0 & 0 & 4 & 1 & 4 & 2 & 4 & 6 & 6 \\
\hline 9 & 0 & 0 & 0 & 0 & 8 & 0 & 7 & 1 & 3 & 8 & 4 \\
\hline & 0 & 3 & 0 & 4 & 5 & 0 & 6 & 3 & 5 & 7 & 8 \\
\hline 10 & 2 & 5 & 0 & 2 & 5 & 2 & 4 & 1 & 4 & 6 & 9 \\
\hline & 1 & 0 & 0 & 0 & 8 & 1 & 11 & 0 & 4 & 6 & 8 \\
\hline Média & 1,2 & 1,55 & 0,5 & 1,25 & 6,45 & 1,2 & 7,05 & 1,4 & 4,4 & 6,45 & 7,2 \\
\hline
\end{tabular}

$\mathrm{CN}$ : Controle negativo. CP: Controle positivo. 


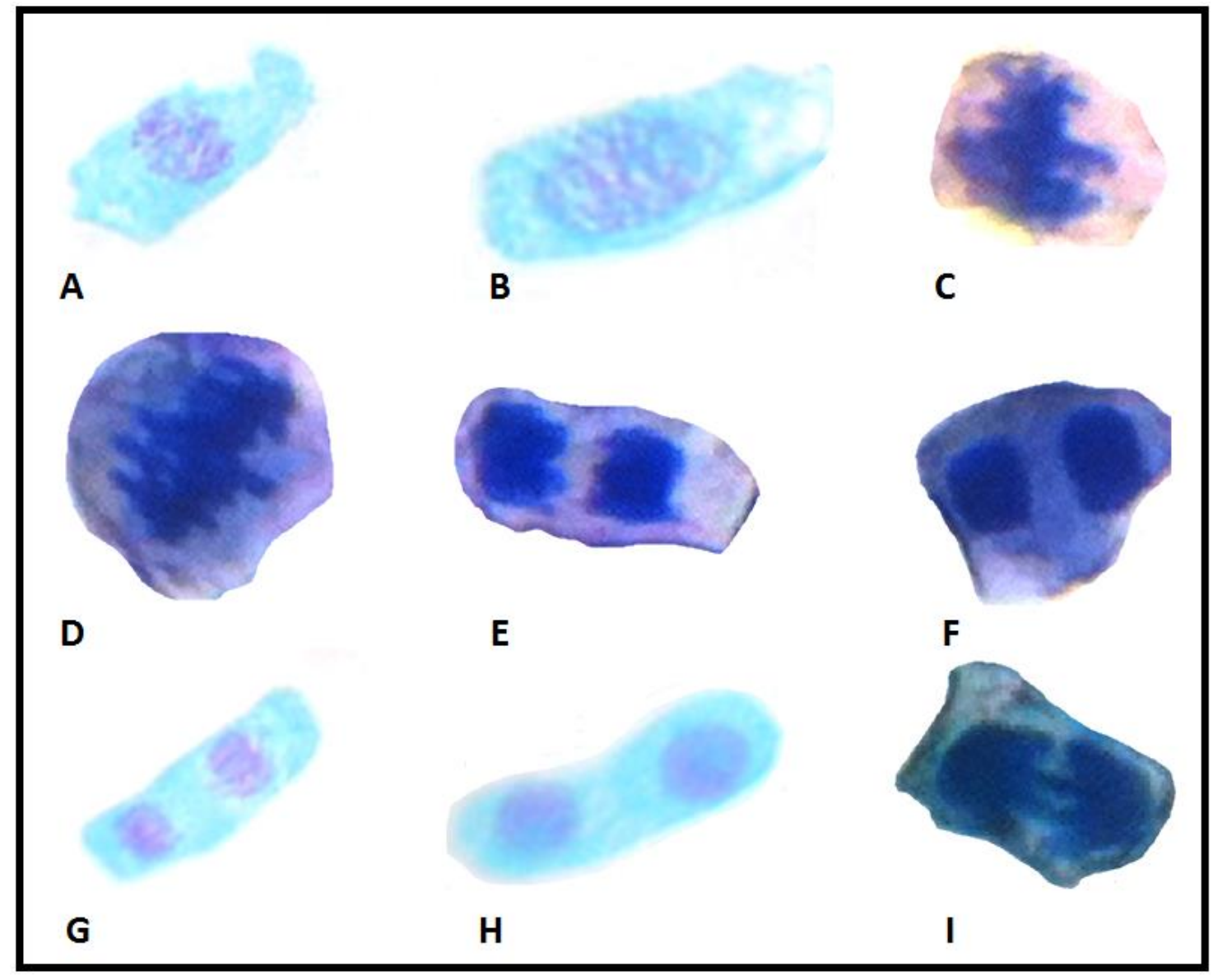

Figura 4. Células de A. cepa em mitose, aumento de 400X. A e B) células em prófase; C e D) células em metáfase; E, F e G) células em anáfase; H) células em telófase; I) ocorrência de ponte anafásica.

Tabela 2. Tratamento, número total de células de A. cepa analisadas no ciclo celular em interfase, prófase, metáfase, anáfase e telófase.

\begin{tabular}{llccc}
\hline Tratamento & \multicolumn{3}{c}{ Número de Células } & $\begin{array}{c}\text { Índice } \\
\text { Mitótico (\%) }\end{array}$ \\
\cline { 2 - 4 } & Total & Interfase & Mitose & 16,40 \\
\hline $\mathrm{CN}$ & 20.000 & 16.720 & 3.280 & $49,11^{\text {*** }}$ \\
\hline $3,85 \mathrm{mg} / \mathrm{mL}$ & 20.000 & 10.177 & 9.823 & 14,99 \\
\hline $38,5 \mathrm{mg} / \mathrm{mL}$ & 20.000 & 17.002 & 2.998 & $9,13^{*}$ \\
\hline $77 \mathrm{mg} / \mathrm{mL}$ & 20.000 & 18.174 & 1.826 & $5,57^{\text {*** }}$ \\
\hline $192 \mathrm{mg} / \mathrm{mL}$ & 20.000 & 18.886 & 1.114 & $4,94^{* * *}$ \\
\hline $\mathrm{CP}$ & 20.000 & 19.011 & 989 & $44,50^{* * * *}$ \\
\hline $\mathrm{CP}+3,85 \mathrm{mg} / \mathrm{mL}$ & 20.000 & 11.099 & 8.901 & $10,33^{* * *}$ \\
\hline $\mathrm{CP}+38,5 \mathrm{mg} / \mathrm{mL}$ & 20.000 & 17.933 & 2.067 & $8,22^{*}$ \\
\hline $\mathrm{CP}+77 \mathrm{mg} / \mathrm{mL}$ & 20.000 & 18.355 & 1.645 & $5,47^{2}$ \\
\hline $\mathrm{CP}+192 \mathrm{mg} / \mathrm{mL}$ & 20.000 & 18.906 & 1.094 & \\
\hline
\end{tabular}




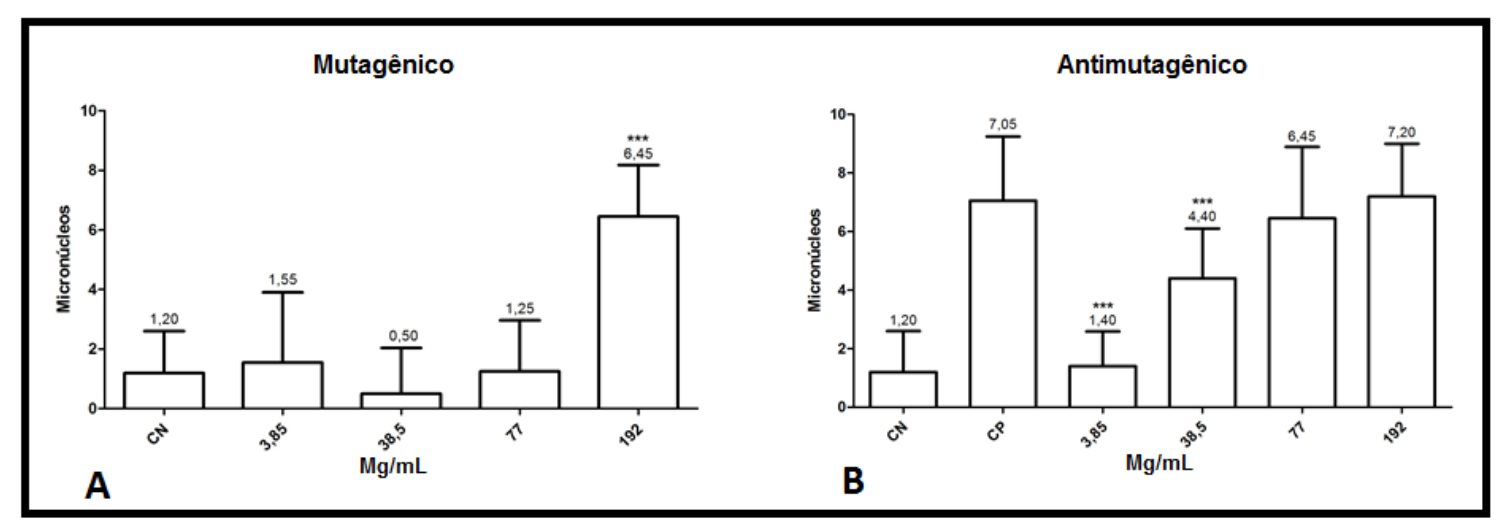

Figura 5. A e B) Média do número de micronúcleos encontrados em 1000 células de A. cepa, germinadas em extrato aquoso de M. guyanensis, para análise mutagênica e antimutagênica. ${ }^{*}(\mathrm{P}<0,05),{ }^{* *}(\mathrm{P}<0,01) \mathrm{e}^{* * *}(\mathrm{P}<0,001)$. $\mathrm{CN}$ : Controle negativo. CP: Controle positivo.

tes na espécie M. ilicifolia (MARIOT; BARBIERI, 2007).

A espécie M. guyanensis produz duas classes de triterpenos na sua entrecasca os friedelanos e os quinonametídeos (HURTADO, 2013), porém poucos são os estudos que enfatizam os efeitos tóxicos e mutagênicos dos triterpenos de maneira isolada.

Composto triterpenoídico maitensina atua in vitro contra células tumorais e em tumores experimentais, onde o extrato de M. ilicifolia apresentou atividade inibitória sobre diferentes sarcomas e células neoplásicas (SANTOS-OLIVEIRA; COULAUD-CUNHA; COLAÇO, 2009), reforçando os resultados antimutagênicos das concentrações 3,85 e $38,5 \mathrm{mg} / \mathrm{mL}$ do extrato aquoso de M. guyanensis, que ocorreu provavelmente devido a presença de friedelanos que também apresentam atividade citotóxica sobre linhagens tumorais in vitro (SHIROTA et al., 1994; ZENG, 1994).

Em outro estudo a espécie $M$. guyanensis também não provocou hemólise em eritrócitos humanos, não apresentou efeito coagulante ou anticoagulante até a concentração de $1 \mathrm{mg} / \mathrm{mL}$ e ainda demonstrou potencial antiagregante possibilitando a utilização dessa espécie para fins farmacológicos (MAIA; LIMA; VASCONCELLOS, 2009).

É importante lembrar que apesar da literatura destacar os triterpenos como principais compostos bioativos da família Celastraceae, a mesma também é rica em sesquiterpenos, que podem ser os principais responsáveis por causarem pequenos danos no DNA quando essas plantas são administradas em concentrações elevadas (CORSINO et al., 1998), como observado no presente estudo com $192 \mathrm{mg} / \mathrm{mL}$.

\section{Conclusão}

O presente estudo demonstrou em células de $A$. cepa incolumidade em relação aos efeitos citotóxicos e mutagênicos em concentrações até 10 vezes maior que a utilizada no uso tradicional de M. guyanensis. São indicados estudos futuros in vitro (linfócitos) e in vivo (camundongos) para uma melhor compreensão dos efeitos fisiológicos dos extratos e compostos isolados, para melhores conclusões sobre o uso seguro da mesma, e até mesmo o desenvolvimento de um fitoterápico ou fármaco tendo esta espécie como matéria prima.

\section{Referências}

BAGATINI, M. D.; SILVA, A. C. F.; TEDESCO, S. B. Uso do sistema de Allium cepa como bioindicador de genotoxicidade de infusões de plantas medicinais. Rev. Bras. Farmacogn, v. 17, n.3, p. 444447, 2007.

BESSEMS, J. G.; GAISSER, H. D.; TE KOPPELE, J. M.; VAN BENNEKOM, W. P.; COMMANDEUR, J. N.; VERMEULEN, N. P. 3,5-Disubstituted analogues of paracetamol. Synthesis, analgesic activity and cytotoxicity. Chem. Biol. Interact, v. 98, n. 3, p. 237-250, 1995.

BORRÁS, M.R.L. Plantas da Amazônia: medicinais ou mágicas - Plantas comercializadas no Mercado Municipal Adolpho Lisboa. Editora Valer/Governo do Estado do Amazonas, Manaus, 2003, 322p.

BRASIL. Agência Nacional de Vigilância Sanitária. Portaria $\mathrm{n}^{\mathrm{o}}$ 116/MS/SNVS/96, de 8 de agosto de 1996, Norma para Estudo da Toxicidade e da Eficácia de Produtos Fitoterápicos. Brasília: ANVISA, 1996.

CAMPAROTO, M. L.; TEIXEIRA, R. O.; MANTOVANI, M. S.; VICENTINI, V. E. P. Effects 
of Maytenus ilicifolia Mart. and Bauhinia candicans Benth infusions on onion root-tip and rat bonemarrow cells. Genet. Mol. Biol, v. 25, n. 1, p. 85-89, 2002.

CANTERLE, L.P. Erva-mate e atividade antioxidante. (Dissertação) Mestrado - Universidade Federal de Santa Maria (UFSM), Santa Maria, Rio Grande do Sul, 2005.

CORSINO, J.; BOLZANI, V. S.; PEREIRA, A. M. S.; FRANÇA, S. C.; FURLAN, M. Further sesquiterpene pyridine alcaloids from Maytenus aquifolium. Phytochem, v. 48, p. 137-140, 1998.

DÜSMAN, E.; BERTI, A. P.; SOARES, L. C.; VICENTINI, V. E. P. Principais Agentes Mutagênicos e Carcinogênicos de Exposição Humana. Rev. Saúde e Biol, v. 7, n. 2, p. 66-81, 2012.

DUTRA, M.G. Plantas medicinais, fitoterápicos e saúde pública: um diagnóstico situacional em Anápolis, Goiás. (Dissertação) Mestrado em Sociedade, Tecnologia e Meio Ambiente - Centro Universitário de Anápolis. Anápolis, Goiás, 2009, 112 p.

FÃO, F.; ZAN, R. A.; BRONDANI, F. M. M.; RAMOS, L. J.; MENEGUETTI, D. U. O. Análise do potencial mutagênico da seiva da casca de Croton lechleri (Müll. Arg), no Estado de Rondônia, Amazônia Ocidental. Rev. Saúde e Biol, v. 7, n. 1, p. 91-98, 2012.

FDA. Food And Drug Administration. Guidance for Industry Safety Testing of Drug Metabolites, 2008, $14 \mathrm{p}$.

FISKESJÖ, G. The Allium test as a standard in environmental monitoring. Hered, v. 102, n.1, p. 99 - 112, 1985.

FISKESJO, G. The Allium Test II: Assesmente of chemical's genotoxic potential by recording aberrations in chromosomes and cell divisions in root tips of Allium cepa L. Environ. Toxicol. Wat. Qual, v. 9, n. 3, p. 234-241, 1994.

FONSECA, A. P. N. D.; SILVA, G. D. F.; CARVALHO, J. J. C.; SALAZAR, G. D. C. M.; DUARTE, L. P.; SILVA, R. P.; TAGLIATI, C. A.; ZANI, C. L.; NEVES, T. M. A.; PERES, V.; VIEIRA-FILHO, S. A. Estudo fitoquímico do decocto das folhas de Maytenus truncata Reissek e avaliação das atividades antinociceptiva, antiedematogênica e antiulcerogênica de extratos do decocto. Quím. Nova, v. 30, n. 4, p. 842-847, 2007.
GIULIETTI, A. M.; HARLEY, R. M.; QUEIROZ, L. P.; WANDERLEY, M. G. L.; BERG, C. V. D. Biodiversidade e conservação das plantas no Brasil. Rev. Megadiver, v. 1, n. 1, p. 54-61, 2005.

HURTADO, F. B. Contribuição ao estudo fitoquímico e biológico da entrecasca da espécie Maytenus guyanensis klotzsh ex Reissek. (Tese) Doutorado em Biologia Experimental - Fundação Universidade Federal de Rondônia (UNIR), Porto Velho, Rondônia, 2013.

LANG, G.; MAYHUNDIN, N.A.; MITOVA, M.I.; SUN, L.; VAN DER SAR, S.; BLUNT, J.W.; COLE, A.L.J.; ELLIS, G.; LAATSCH, H. \& MUNRO, M.H.G. Evolving trends in the dereplication of natural products extracts: New methodology for rapid, small-scale investigation of natural products. J. Nat. Prod, v. 71, n. 9, p. 1595-1599, 2008.

LIÃO, L. M. Triterpenos quinonametideos de Salacia campestris (Hippocrateaceae). (Dissertação) Mestrado em Química, Universidade Federal de São Carlos, São Paulo, 1994.

LIÃO, L.M. Alcaloides Sesquiterpênicos Piridínicos e Triterpenos Quinonametídeos Degradados de Salacia campestris (Hippocrateaceae). (Tese) Doutorado em Ciências (Química Orgânica) Universidade Federal de São Carlos, São Paulo, 1997.

LORENZI, H.; MATOS, F. J. A. Plantas Medicinais no Brasil: Nativas e exóticas. Ed. $2^{\circ}$. Nova Odessa: Plantarum, 2008, 608p.

MAIA, B.L.; LIMA, E. S.; VASCONCELLOS, M. C. Avaliação da Atividade Hemolítica, Coagulante e Antiagregante Plaquetária do Extrato Seco da Casca de Maytenus guyanensis. 61ํㅡ Reunião Anual da SBPC, 2009.

MARIOT, M.P.; BARBIERI, R.L. Metabólitos secundários e propriedades medicinais da espinheira-santa (Maytenus ilicifolia Mart. ex Reiss. e Maytenus aquifolium Mart.). Rev. Bras. Pl. Med, v.9, n.3, p.89-9, 2007.

MENEGUETTI, D. U. O.; SILVA, F.C.; ZAN, R.A.; RAMOS, L.J. Adaptation of the micronucleus technique in Allium cepa, for mutagenicity analysis of the Jamari river valley, western Amazon, Brazil. J Environ. Anal. Tox, v. 2, n.2, 2012.

OLIVEIRA, J.M.; YAMASHITA, M.; MENEGUETTI, D. U. O. Análise do Potencial Mutagênico em Afluentes do Rio Boa Vista Influenciados Pela 
Emissão de Rejeitos de Uma Indústria de Laticínios no Município de Ouro Preto do Oeste RO, Brasil. In: VIII Jornada Científica Centro de Estudos Interdisciplinar em Desenvolvimento Sustentável da Amazônia. E-book VIII Jornada Científica do CEDSA, v. 8. p. 73-88, 2013.

POLETTO, P. O.; DINIZ, A. P.; BERNARDON, B.; ZAN, R. A.; RAMOS, L. J.; MENEGUETTI, D. U. O. Análise da mutagenicidade do extrato hidrossolúvel de Derris rariflora (Mart. Ex Benth. J. F. Macbr: Fabaceae), timbó amazônico, através do teste micronúcleo em Allium cepa. Rev. Pesq \& Criação, v. 10, n. 1, p.163-175, 2011.

REID, K. A.; MAES, J.; VAN STADEN, J.; DE KIMPE, N.; MULHOLLAND, D. A.; VESCHAEVE, L. Evaluation of the mutagenic and antimutagenic effects of South African plants. Jour. of Ethnopahar, v. 106, n.1, p. 44-50, 2006.

REVILLA, J. Apontamentos para a cosmética amazônica. SEBRAE-AM/INPA, Manaus, 2002, 532pp.

RODRIGUES, S. B. V.; MIRANDA, R. R. S.; DUARTE, L. P.; SILVA, G. D. F.; OLIVEIRA, D. M.; LULA, I. S. Triterpenos pentaciclicos isolados de Salacia elliptica (Mart.) Peyr. 29ํㅡㄹ Reunião Anual da Sociedade Brasileira de Química (SBQ). Belo Horizonte, Minas Gerais, 2006.

SANTOS-OLIVEIRA, R.; COULAUD-CUNHA, S.; COLAÇO, W. Revisão da Maytenus ilicifolia Mart. ex Reissek, Celastraceae. Contribuição ao estudo das propriedades farmacológicas. Rev. Bras. Farmacogn, v. 19, n. 2B, p. 650-659, 2009.

SHIROTA, O.; MORITA, H.; TAKEYA, K.; ITOKAWA, H. Cytotoxic aromatic triterpenes from Maytenus ilicifolia and Maytenus chuchuhuasca . Phytochem, v. 57, n. $12,1675-1681,1994$.

SILVA, A. M. ; SOUZA, A. M. ; MACIEL, F. P. ; DINIZ, A. P. ; ZAN, R. A. ; RAMOS, L. J. ; BARBOSA, N. V. ; MENEGUETTI, D. U. O. . Analysis Physicalchemical, Mutagenic and Antimutagenic de Morinda Citrifolia L. (Rubiaceae: Rubioideae) Noni, Germinated in the Region of Brazilian West Amazon. O. A. Scien. Rep, v. 1, p. 569, 2012.

SILVA, J. A.; COSTA, R. S.; MARIANO, A. S.; SANTOS, K. L. S.; SILVA, C. O. J. Análise farmacognóstica de amostras de espinheira santa Maytenus ilicifolia (Schrad.) Planch. (Celastraceae) comercializadas em farmácias e banca popular de Votuporanga - São Paulo. Rev. Bras. Farmacogn, v.93, n.4, p.457-462, 2012.

SILVA, L. R.; FERREIRA, M. M. C. Estudo do coeficiente de partição octanol-água de bifenilas policloradas (PCBs) utilizando parâmetros topológicos. Quím. Nova, v. 26, n. 3, p. 312-318, 2003.

SOUZA, S. A. M.; STEIN, V. C.; CATTELAN, L. V.; BOBROWSKI, V. L.; ROCHA, B.H.G. Utilização de sementes de alface e de rúcula como ensaios biológicos para avaliação do efeito citotóxico e alelopático de extratos aquosos de plantas medicinais. Rev. Biol. Ciên. Terra. Belo Horizonte. v. 5, n. 1, p. 3-9, 2005.

STURBELLE, R.; PINHO, D. S.; RESTANI, R. G.; OLIVEIRA, G. R.; GARCIAS, G.L.; MARTINOROTH, M.G. Avaliação da atividade mutagênica e antimutagênica da Aloe vera em teste de Allium cepa e teste de micronúcleo em linfócitos humanos binucleados. Rev. Bras. Farmacogn, v. 20, n.3, p. 409-415, 2010.

TEIXEIRA, R.O.; CAMPAROTO, M.L.; MANTOVANI, M.S.; VICENTINI, V.E.P. Assessment of two medicinal plants, Psidium guajava L. and Achillea millefolium L. in in vivo assays. Genet. Mol. Biol, v. 26, n.4, p. 551-555, 2003.

ZENG, C.Q. Cytotoxic triterpenoids and flavonoids from. Plant. Med, v. 60, n.1, p. 54-57, 1994. 